\title{
Interspecific discovery and expression profiling of Eucalyptus micro RNAs by deep sequencing
}

\author{
Marília Pappas ${ }^{1 *}$, Alessandra Reis ${ }^{2}$, Laurent Farinell ${ }^{3}$, Giancarlo Pasquali ${ }^{4}$, Georgios Pappas $\mathrm{Jr}^{1}$, Dario Grattapaglia ${ }^{1}$ \\ From IUFRO Tree Biotechnology Conference 2011: From Genomes to Integration and Delivery \\ Arraial d'Ajuda, Bahia, Brazil. 26 June - 2 July 2011
}

\section{Background}

Micro RNAs (miRNAs) are a class of small ( 21 nucleotide) non-coding RNAs that recently gained much attention due to their perceived role as master regulators of gene expression in Eukaryotes, responsible for fine tuning gene expression regulation and, in plants, has been shown to be involved in a diverse range of biological processes such as plant development and architecture, flowering, cell differentiation and response to biotic and abiotic stresses [1]. The repertoire of expressed miRNAs differs among cell types, tissues, development, environmental condition, etc [2]. Notwithstanding, the exact function of thousands miRNAs sequences present in miRBase [http://www.mirbase.org/] is not elucidated. At this point, discovery and profiling of new and conserved miRNAs are critical in the attempt to understand their function and mechanism. Deep sequencing through next generation sequencing is the methodology of choice for this purpose as its ultra high throughput permits a comprehensive interrogation of the small RNA transcriptome, permitting de novo identification and relative quantification of different small RNA species [3].

Due to its economic importance the Eucalyptus grandis genome has been sequenced by JGI and the annotation of miRNAs is pivotal. In order to provide the first large scale experimental characterization of Eucalyptus miRNAs we performed an Illumina deep sequencing run that allowed us to discover and quantify the miRNA levels in two different tissues - xylem and leaves. Additionally, to get insights of the observed phenotypic differences in wood quality among Eucalyptus species, we characterized the xylem small RNA transcriptome of two different E. globulus individuals and

* Correspondence: mariliac@cenargen.embrapa.b

1 Embrapa Genetic Resources and Biotechnology, Brazil

Full list of author information is available at the end of the article integrated the results to catalog conserved and Eucalyptus specific miRNA gene families.

\section{Materials and methods}

Four biological samples were used: xylem from two $E$. globulus genotypes, xylem and leaf from BRASUZ1 $E$. grandis, the one currently being sequenced by JGI. Total RNA extraction was performed with CTAB protocol to a total amount of $10 \mathrm{mg}$ per sample [4]. Fraction of small RNAs were barcoded to be sequenced in a single flow cell in Illumina GA II Sequencing System by Fasteris [http://www.fasteris.com]. A computational pipeline was specifically developed to process the deep sequencing data. The pre-processing step cleans the sequences by quality screening, adapter sequence removal, contaminant checking. Cleaned reads were sorted according to size, quantified (tag counting) and used to create an additional set of non-redundant sequences (using uclust). Bowtie was used to map sequences against the $8 \mathrm{X}$ E. grandis - BRASUZ1 genotype - genome sequence draft. Mapped positions in the genome were extended by 150 bases to be used as input to predict secondary structure (miRDeep) to test for stem loop structure of miRNA precursors. Northern blot hybridization is being used for experimental validation of some conserved and potentially new Eucalyptus miRNAs sequences.

\section{Results and conclusions}

Total number of reads was 6,104,498 ranging from $1,115,404$ to $1,766,355$ per sample - $36 \mathrm{nt}$ average size. After pre-processing, total number of sequences was reduced to $1,980,958$. As expected, read size distribution has two main peaks at 21 and $24 \mathrm{nt}$. Comparative analysis of size distribution interestingly shows higher abundance of the $24 \mathrm{nt}$ fraction for all samples, being up to 3,75 times higher than $21 \mathrm{nt}$. The $24 \mathrm{nt}$ small RNAs are predominantly small interfering RNAs (siRNAs) which 
are involved in RNA-directed DNA methylation resulting in gene and transposon silencing. Putting it all together, reads from four samples resulted in 169,642 unique sequences mapped against the genome. From that, $70,55 \%$ had at least one alignment to the genome reported, $23,54 \%$ failed to align and 5,91\% mapped to multiple loci, indicative of repeat regions.

Mapping 20-22 nt reads against the reference genome revealed that BRASUZ1 had more reads mapping to its own genome than the other samples, totaling $95 \%$ for leaves sample and $91 \%$ for the xylem. E. globulus samples showed a reduced percentage of mapped reads, around $85 \%$, corroborating the existence of interspecific variability. Besides that, the relative abundance among the three xylem samples reinforces the variability also in the expressed repertoire of small RNAs.

Annotation of plant miRNAs was done meeting a set of strict criteria, particularly a proper secondary structure of the precursor [5]. The positions in the genome with a mapped reads were extended to 300 bases and fed to the program miRDeep [6] to test for the compatibility of precursor hairpin. At least 38 sequences mapped were positive under these premises.

Conserved Eucalyptus miRNAswere identified by similarity searches against the miRBase. A total of 206 distinct Eucalyptus sequences showed significant similarity (at most one mismatch) to an orthologous sequence, confirming the presence of 36 different mir genes families, including many of its isoforms.

Quantitative differences in miRNA abundance were probed by pairwise comparison of tag counts contrasting intraspecific, interspecific and tissue-specific analysis. Results revealed that the most similar small RNA repertoire are between intraspecific samples and, the least, between tissue specific. Tissue specific differential expression analysis shows that around $36 \%$ of the conserved miRNAs sequences observed in each tissue was mutually exclusive and the ones present in both samples vary up to two-fold ( $\mathrm{p}$-value $=0.05$ ).

Experimental validation is being carried out by northern blot hybridization and preliminary results validated new and conserved miRNAs, such as mir 156 and mir 172.

\footnotetext{
Acknowledgments

This work was supported by the Brazilian Ministry of Science and

Technology through CNPq grant 577047/2008-6 and FAP-DF Grant NEXTREE
}

193.000.570/2009 and EMBRAPA Macroprogram 2 project grant 02.07.01.004.

\section{Author details}

${ }^{1}$ Embrapa Genetic Resources and Biotechnology, Brazil. ${ }^{2}$ Catholic University of Brasília, Brazil. ${ }^{3}$ Fsateris SA, Brazil. ${ }^{4}$ Federal University of Rio Grande do Sul, Brazil.

Published: 13 September 2011
References

1. Axtell M, Snyder J, Bartel D: Common functions for diverse small RNAs of land plants. Plant Cell 2007, 19:1750-1769.

2. Creighton C, Reid J, Gunaratne P: Expression profiling of microRNAs by deep sequencing. Brief Bioinform 2009, 10(5):490-497.

3. Meyer S, Pfaffl M, Ulbrich S: Normalization strategies for microRNA profiling experiments: a 'normal' way to a hidden layer of complexity? Biotechnol Lett 2010, 32:1777-1788.

4. Chang S, Puryear J, Cairney J: A simple and efficient method for isolating RNA from pine trees. Plant Molecular Biology Reporter 1993, 11(2):113-116.

5. Meyers BC, Axtell MJ, Bartel B, Bartel DP, Baulcombe D, Bowman JL, Cao X, Carrington JC, Chen X, Green PJ, et al: Criteria for Annotation of Plant MicroRNAs. Plant Cell 2008, 20:3186-3190.

6. Friedländer M, Chen W, Adamidi C, Maaskola J, Einspanier R, Knespel S, Rajewsky N: Discovering microRNAs from deep sequencing data using miRDeep. Nature Biotechnology 2008, 26:407-415.

doi:10.1186/1753-6561-5-S7-P173

Cite this article as: Pappas et al:: Interspecific discovery and expression profiling of Eucalyptus micro RNAs by deep sequencing. BMC

Proceedings 2011 5(Suppl 7):P173.

\section{Submit your next manuscript to BioMed Central} and take full advantage of:

- Convenient online submission

- Thorough peer review

- No space constraints or color figure charges

- Immediate publication on acceptance

- Inclusion in PubMed, CAS, Scopus and Google Scholar

- Research which is freely available for redistribution

Submit your manuscript at www.biomedcentral.com/submit
Ciomed Central 